\title{
Un corredor verde entre cerros desde 1934, y las posibilidades actuales desde un ejercicio académico de pregrado en Recoleta.
}

A green corridor between the hills since 1934, and its current possibilities, explored through an undergraduate academic exercise in Recoleta.

María Isabel Pavez Reyes

\section{Filiación}

Dr. Arquitectura y Urbanismo, Profesora Titular D. de Urbanismo, F.A.U. U. de Chile.

E mail: mpavez@uchilefau.cl

\section{Resumen}

En el marco de una investigación FAU -U. Chile, "El antiguo sector de La Chimba: en defensa de sus vestigios patrimoniales, una vida comunitaria de escala barrial y un futuro ambiente sustentable"1 , y la reconsideración de una proposición de Karl Brunner en Recoleta, un grupo de estudiantes exploran un polígono del pericentro norte de Santiago, presentando las posibilidades y limitaciones actuales para lograr una cierta continuidad verde entre los cerros San Cristóbal y Blanco en la perspectiva de una renovación con mayor sustentabilidad urbana.

\section{Palabras claves}

Karl Brunner; Recoleta-Santiago de Chile; Planificación y Diseño Urbano; corredor verde urbano.

\begin{abstract}
This article is part of the research project entitled "The old area of La Chimba: in defense of its heritage traces, a neighborhood scale community life and a sustainable environment for the future" (funded through the Universidad de Chile's Faculty of Architecture and Urbanism research fund). A group of undergraduate architecture students revisit a proposition made by Karl Brunner for Recoleta, exploring the possibilities and limitations to achieve a continuity of green spaces between the San Cristobal and Blanco hills, from an urban sustainability perspective.
\end{abstract}

\section{Key words}

Karl Brunner; Recoleta - Santiago de Chile; Urban Planning; urban green corridor.

\footnotetext{
1 Investigadora Responsable: Mag. Geo. Carolina QUILODRÁN RUBIO (Instituto de Historia y Patrimonio). Coinvestigadores: Dr. Antonio SAHADY VILLANUEVA (Instituto de Historia y Patrimonio), Dra. María Isabel PAVEZ REYES (Departamento de Urbanismo), José BRAVO SÁNCHEZ (Instituto de Historia y Patrimonio), Diego VALLEJOS OBERG (Departamento de Urbanismo), No Proyecto: 02/12, término en nov. 2013.
} 


\section{Sumario}

Introducción

1 Plano Oficial de Urbanización de la Comuna de Santiago 1934 - Polígono de Recoleta.

2 Continuidad de la masa verde en el bloque norte de Santiago en el plan Muñoz, desde 1936.

3 Lo realizado del plan Brunner en el polígono de Recoleta e intervenciones posteriores

4 Ejercicios académicos y un proyecto profesional en el entorno del cerro Blanco.

4.1 Los trabajos de los viejos estudiantes en 1930

4.2 Anteproyecto de Ciudad Universitaria junto al cerro-parque Blanco para la Universidad de Chile en los 50'.

4.3 Exploración de Diseño Urbano entre los cerros-parques San Cristóbal y Blanco en un ejercicio académico del pregrado en 2013

Palabras finales

Bibliografía

\section{Introducción}

En los momentos en que el primer grupo de arquitectos alumnos del Seminario de Urbanismo para pos-titulados -dictado por el arquitecto y urbanista austríaco Karl Brunner en la Universidad de Chile² - terminaba su año escolar en enero de 1931, la Dirección de Obras de la Ilustre Municipalidad de Santiago inauguraba una exposición de Urbanismo y Edificación, la que se sumaba a muchas publicaciones de prensa "alentadoras" -según Brunner- pues divulgaban en alto grado las tendencias y experiencias en arquitectura, urbanización y habitación obrera.

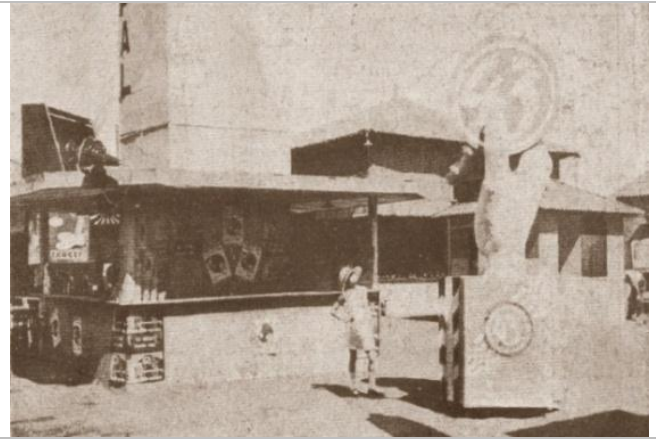

Fig. 1.- Exposición municipal de Urbanismo y Edificación en Santiago de Chile, enero de 1931. Foto K. Brunner [Su hija Magda en la imagen].

Fte.: Brunner, 1932, p.103.

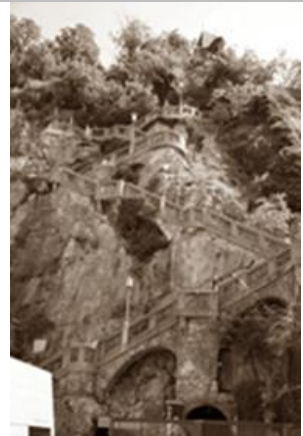

Fig. 2.- Detalle en la colina de Graz. Foto: Ntinos Lagos. Fte.: Panoramio, 2308-2013.

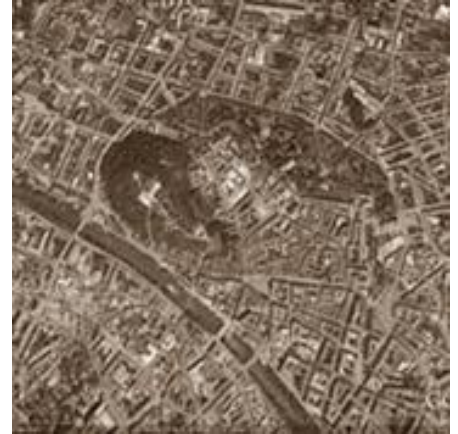

Fig.3.- La colina de Graz junto al río, Austria.

Foto vertical Google Earth, en sepia, 2308-2013.

2 En el urbanista austríaco Karl Brunner (1887-1960), se reconoce la impronta de la escuela de Cambridge (U.S.A.) sobre una concepción técnica y científica del Urbanismo; también de los movimientos City Beautiful y Landscape, así como del arquitecto Olmstead sobre la importancia del sistema de parques, y de Unwin respecto de la relación ciudad y naturaleza (Cortés, 1996). Realizó en sus dos misiones en Chile diversos estudios y anteproyectos para la ciudad de Santiago, pero no desarrolló un proyecto intercomunal propiamente tal, pues el correspondiente escalón de la planificación urbana no era reconocido aún. 
Desde su llegada a Santiago, Brunner había reparado en los cerros existentes en el centro y pericentro de Santiago. Señalaba sobre el cerro Santa Lucía que le recordaba la colina-parque junto al río de la ciudad de Graz, en Austria, imaginando igual condición verde para el cerro Blanco en la futura Santiago metropolitana.

Pero, la condición de cerros-parques deseable no era suficiente según sus conceptos, pues era necesario potenciar los recursos verdes ligándolos ${ }^{3}$.

En la segunda ciudad de Austria, la ciudad de Graz, capital de Estiria, que panorámicamente presenta mucha semejanza con Santiago, desde años se persigue la política de un sistema unido de plantaciones, habiéndose ya unido el Schlossberg, el Santa Lucía de Graz, plantado en forma de parque con el Parque Municipal y actualmente se prosigue extendiendo el área verde a lo largo del río hacia el interior de la ciudad. 4

Brunner encontró en el polígono de Recoleta una "Avenida de Circunvalación", con 500 m de longitud (tramo de la actual Avda. Perú, entre San Cristóbal y Rapa-Nui), con un perfil equivalente a las más antiguas e importantes calles de la zona norte, (Fig.4).

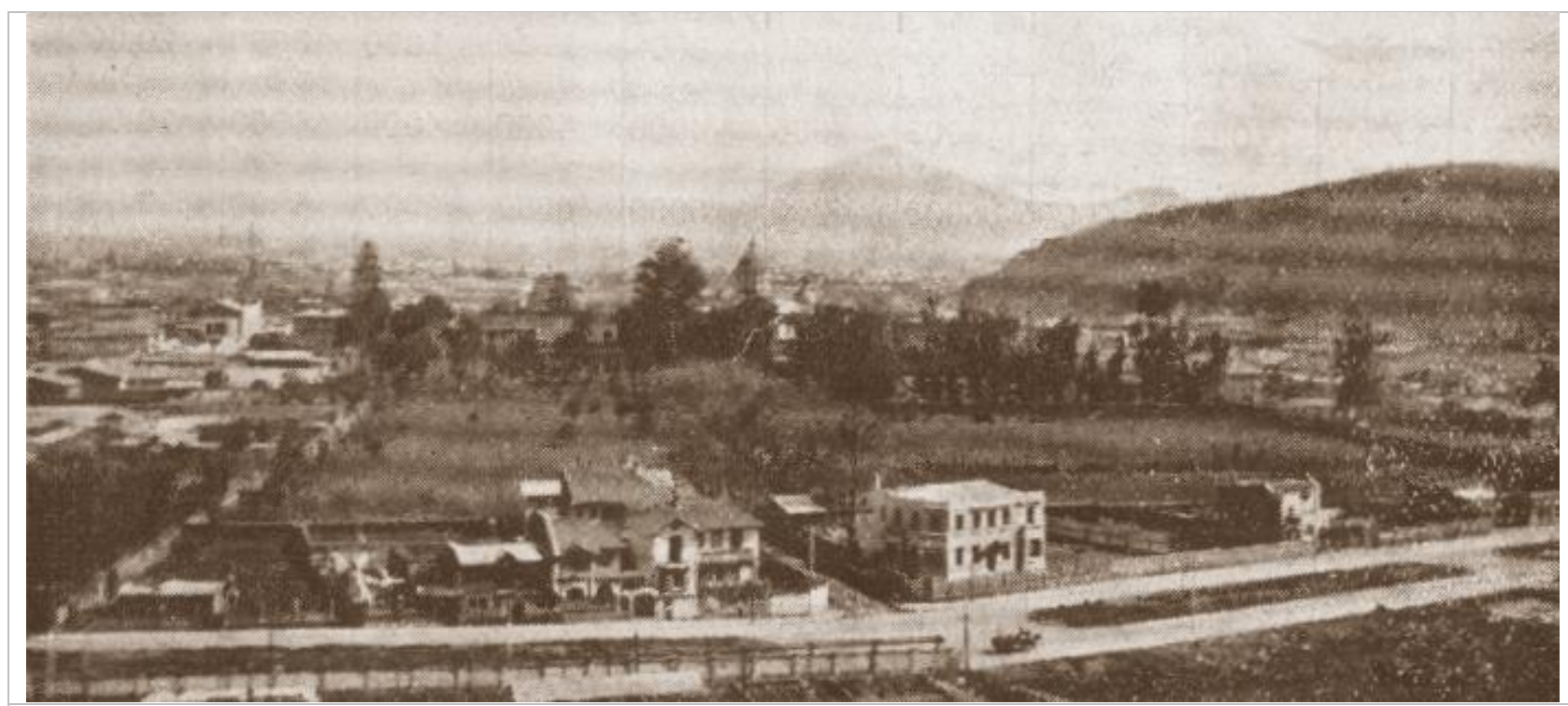

Fig.4.-"Avenida de Circunvalación" (Avda. Perú)

Fte: Brunner, 1932, p.108

Esta y otras avenidas anchas de Santiago (Av. Cumming, Av. Vicuña Mackenna, pasado la Avda. Matta) se habían realizado en barrios obreros, con grandes gastos, sin que resultara una valorización apreciable de los terrenos, porque los alrededores no lo permitían y se admitió en ellos toda clase de edificaciones y usos de suelo 5 .

3 En 1931 los parques más importantes de Santiago sumaban 100 hectáreas. Para 1 millón de habitantes Brunner calculó la necesidad de 400 hectáreas ( $4 \mathrm{~m}^{2}$ por hab.).

4 BRUNNER, op. cit. 1930, pp. 31.

5 Brunner, 1932, p.14. 
La "Avenida de Circunvalación" pareció a Brunner una equivocación completa, pues el motivo en su denominación no podía realizarse ya que no tenía un arranque adecuado, ni se podía prolongar hacia el nor-oeste estando allí el cerro Blanco y el Cementerio General ${ }^{6}$.

En cuanto a la continuación de la "Avenida de Circunvalación" al norte, sería difícil pues requeriría la expropiación de un molino, y del predio que ocupaba el Club Nacional de Tiro, y, al estar las manzanas del norte pobladas por gente modesta, el carácter del área no se prestaba en opinión de Brunner para desarrollar una avenida "elegante y pretenciosa". El recorrido desde el centro hasta el barrio El Salto, ya se hacía fácilmente por las avenidas Recoleta y El Salto ${ }^{7}$.

\section{Plano Oficial de Urbanización de la Comuna de Santiago 1934 - Polígono de Recoleta.}

En una Segunda Misión, el contrato entre Brunner y la I. Municipalidad de Santiago dio lugar a un proyecto de planificación para esta comuna, cuando sus límites se ubicaban en el cerro San Cristóbal y la Estación de Pirque, por el oriente; a $200 \mathrm{~m}$ al norte del Hipódromo Chile, por el norte; a $1.300 \mathrm{~m}$ al sur del parque Cousiño, por el sur, y a unos $1.500 \mathrm{~m}$ al poniente de la Estación Central de Ferrocarriles, por el poniente. (Fig.5).

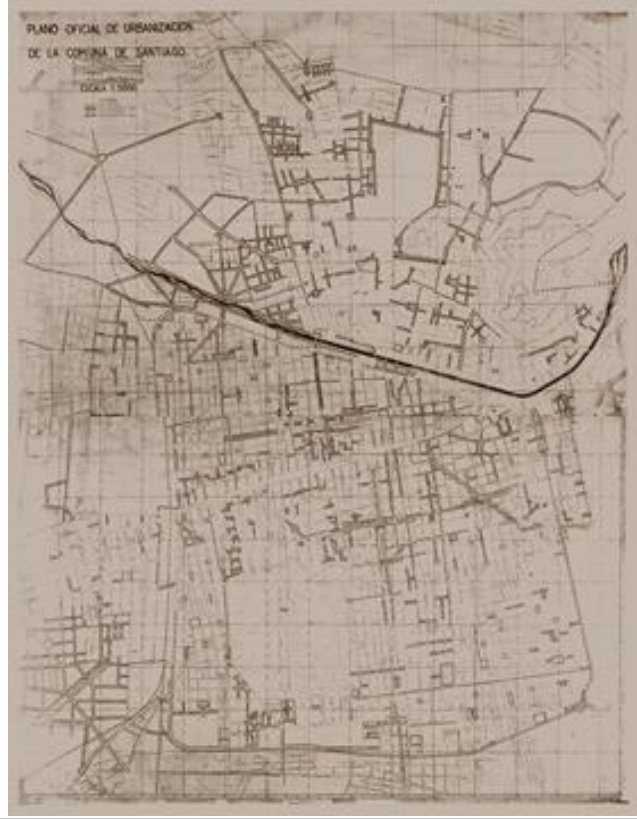

Fig.5.- Plano Oficial de Urbanización de la Comuna de Santiago. K.H. Brunner 1934. Escala original 1:5.000.

Copia matriz en Archivo D. Urbanismo, F.A.U., U. Chile.

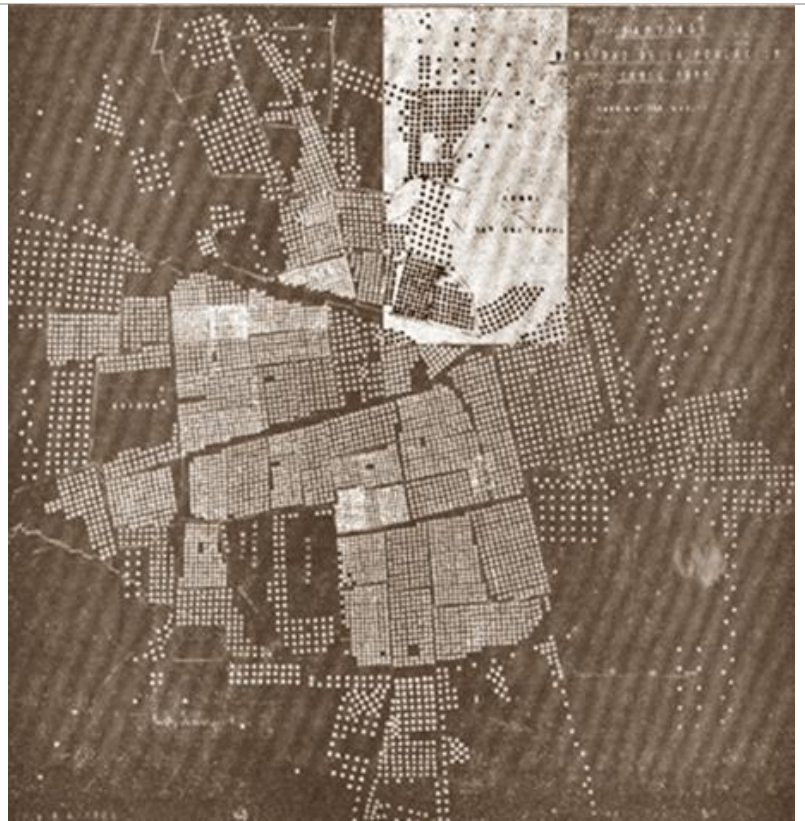

Fig.6.- Densidad de población de Santiago, 1930. Un punto: 100 habitantes. (Primera Misión. Brunner, 1932).

Nota: Contrastado inversamente en el polígono de Recoleta, para esta publicación.

El polígono de Recoleta, en el entorno inmediato del cerro Blanco, presentaba densidades de población medias a bajas en 1930, comparadas con otras zonas de Santiago, Fig.6. No

6 Señaló, en cambio, como semi-circunvalación norte la combinación O’Higgins - Gamero (en el futuro desde el puente Bulnes) -Santos Dumont - "Avenida de Circunvalación"- Domínica - Pío Nono. Este sistema permitiría la desviación del tránsito externo hacia las distintas partes de la ciudad.

7 Brunner, 1932, op.cit. 
obstante, Brunner estimó que en ciertas zonas al pie del San Cristóbal se iban produciendo viviendas en una densidad de ocupación de suelo excesiva, Fig.7.

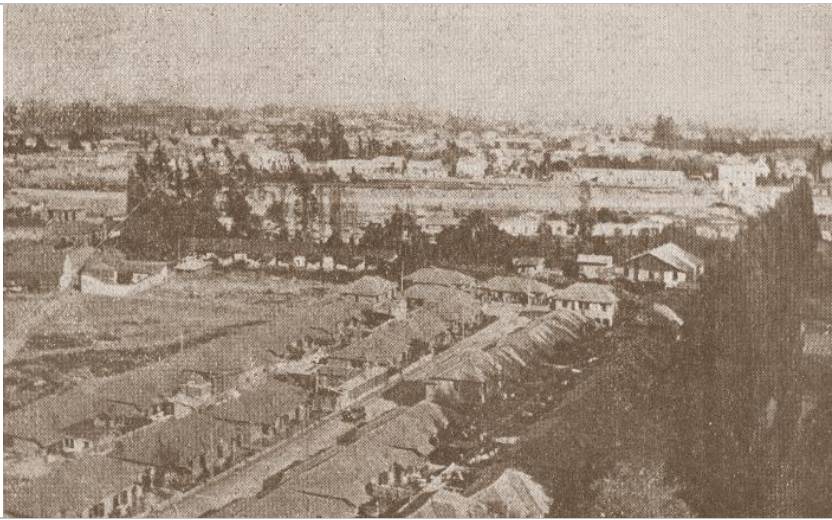

Fig.7.- "Población el pie del San Cristóbal, con edificación demasiado densa". Foto: K. Brunner. Fte.: Brunner, 1932, p.98.

Estimó Brunner que la comuna de Santiago poseía ya suficientes grandes áreas verdes (sobre 12 hás.) -comprendido el cerro Blanco como futuro espacio verde- y que solo cabía constituirlas o mantenerlas; nuevos espacios verdes mayores tendrían que ubicarse en las comunas que rodeaban la comuna de Santiago, en la perspectiva de la configuración de Santiago como metrópolis. En cambio, señaló carencias en lo referido a parques menores y plazas públicas en los barrios con residentes ${ }^{8}$.

Así, a partir de las vías existentes, y proponiendo ensanches, prolongaciones, y algunas aperturas, Brunner trazó espacios públicos viales y de recreación en las escalas de barrio y vecindad, con respeto por lo existente bien logrado en Recoleta, Fig.8.

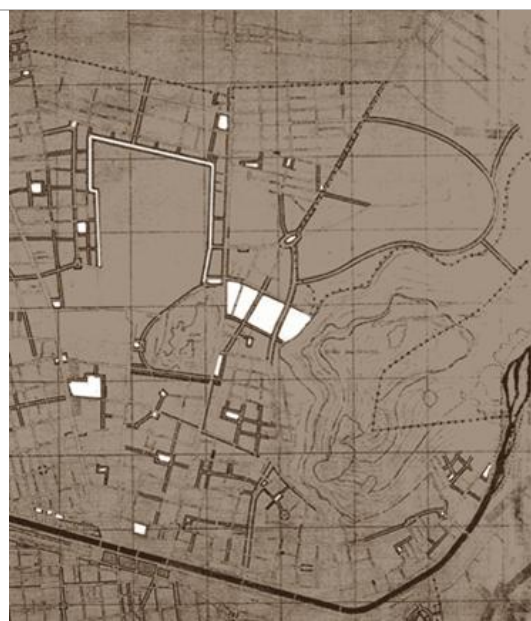

Fig.8.- Sección del plano P.O.U. Brunner 1934/39 -polígono Recoleta-. (C) Fte: Elaboración propia a partir de copia matriz.

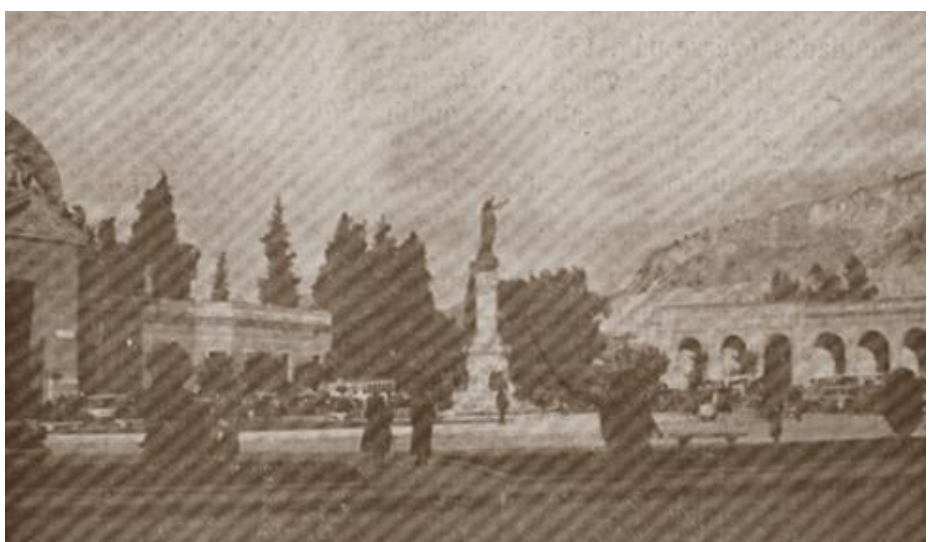

Fig. 9.- Parte de la masa verde del Cementerio General y su relación con el cerro Blanco (a la derecha, al fondo), futuro parque de la ciudad, en Brunner.

Fte.: Brunner, 1932.

Nota: En Fig. 8.- Vialidad, vías-jardín, plazas, y parques locales propuestos por K.B., con remarcado del plano original. / Superficies en blanco: espacios verdes públicos propuestos por K.B. (se incluye jardín en perfil de vía rodeando el Cementerio General); así destacados para la presente publicación.

8 Brunner, 1932, p.23. 
Dispuso Brunner, en primer lugar, un parque de 12 hectáreas en la zona de más baja densidad ("barrio obrero" en su expediente), el que uniría los cerros San Cristóbal y Blanco, Fig.8.

Se observará que, a la disposición de un parque de unión entre los cerros San Cristóbal y Blanco, asumidos estos últimos como futuros parques, se sumaría también la masa verde del Cementerio General, Fig.9.

Este parque quedaría conformado por cuatro secciones a partir de la existencia y rediseño de dos vías de cierta importancia, como eran Avda. Perú (prolongación al norte, de "Avda de Circunvalación"), y Puma (prolongación al sur hasta plaza articuladora con S. Dumont). Una tercera vía de importancia solo local, que dividía el parque era la actual calle llamada hoy "El Salto Chico".

De esta forma el parque de 12 hás propuesto tendría 4 sub-áreas de unas 3 hás cada una, esto es un conjunto a escala de conjunto de barrios, de tamaño y dispersión media, relevante al desarrollo de la civilidad.

Brunner discutió el trazado de ciertas manzanas al pie del San Cristóbal (frente a la "Avenida de Circunvalación") ${ }^{9}$ :

No parece tampoco satisfactorio el trazado de los bloques en el pie del cerro San Cristóbal. Aquí se debería haber exigido un trazado más pintoresco con intercalación de subidas arquitectónicas o a lo menos de vialidad conveniente.

No obstante, indicó que había que ordenar la urbanización de, al menos, parte de sus faldeos - de donde se obtendría recursos para las instalaciones más allá de la ornamentación ya existente en la parte alta-; en el faldeo poniente (Recoleta) se debía tener en cuenta la existencia de la línea de alta tensión (Brunner 1932), respecto de la cual era necesario mantener una distancia y, en ningún caso sobrepasarla ${ }^{10}$.

También en su conferencia en la Universidad de Chile en 1930, había recomendado huertos obreros de arriendo en los faldeos del San Cristóbal' ${ }^{11}$ :

Este sistema de plantaciones de las ciudades debería incrementarse, además, fomentando por todos los medios la creación de pequeños jardines de arriendo para obreros. El acostumbrar a las clases obreras al cultivo de estos jardines ha nacido en Holanda e Inglaterra, habiéndose generalizado después en toda la Europa central, y constituye un factor ético y económico-social en la educación popular y un medio de higienización para las nuevas generaciones. Se ha comenzado ya con estos jardines en los faldeos del San Cristóbal, lo que demuestra la manera cómo una gran parte de sus faldeos podría ser aprovechada. Estos jardines hacen recordar una plantación de jardines para obreros que fue ejecutada hace poco en el faldeo de un cerro de Reimscheit, (Departamento del Rhur).

En segundo lugar, junto con proponer varias vías locales, centralidades de barrios y vecindades, dispuso espacios verdes menores asociados a ellas, aportando a la 'paseabilidad' peatonal de Recoleta, e incrementando la visibilidad de los macro paisajes al oriente y poniente. También algunas conexiones secundarias necesarias, diversas islas para ordenamiento de la circulación motorizada, y una vía-jardín rodeando el Cementerio General. Esta última sería línea de frontera permitiendo al frente residencial tomar distancia del muro

9 Brunner, 1932, p. 41.

10 En la actualidad sobrepasada. Algunas torres de alta tensión incluso acometen con sus bases en patios privados de vivienda para población de escasos recursos, legitimadas en sitio por los "Pavimentos Participativos" de la vialidad local de acceso (Programas del MINVU).

11 BRUNNER, op. cit. 1930, pp. 32. 
con nichos que rodea el camposanto, y contar con una cortina verde como micropaisaje mediante el arbolado en su eje, Fig.8.

Destaca también la articulación (plaza lineal y vías de entorno) entre el eje oriente-poniente Gamero - Santos Dumont (ajardinada por Brunner entre Avda. la Paz y Recoleta), y "Avenida León" (actual Puma) de sentido norte-sur, cuyo tramo existente fue prolongado al sur para alcanzar la plaza-rótula dispuesta. Se aprovechó así la existencia de un tramo que ya acometía por el norte en un punto de confluencia de varias vías, tanto existentes como propuestas, y que dieron lugar al diseño de una rotonda ordenadora de circulación sobre la avenida Valdivieso.

Finalmente, al proyecto de una vía local curva trazada en el borde poniente del cerro Blanco, uniendo los extremos de la calle recta Monserrat, se asoció una plaza en su punto medio, con frente también a avenida La Paz, aproximando, de esta forma, el espacio verde imaginado para el cerro Blanco a la vía ceremonial que remata en el acceso del Cementerio General.

\section{Continuidad de la masa verde en el bloque norte de Santiago en el plan Muñoz, desde 1936.}

El parque antes referido fue confirmado en el plan intercomunal dispuesto por Muñoz Maluschka12, desde c. 1936, con el que este planificador orientó -en su calidad de Jefe de la Sección de Urbanismo de la D.G.O.P.- los crecimientos y ordenamiento del gran Santiago, cuando aún no había la figura legal para la planificación de dicho escalón territorial. Él mismo logrará este instrumento en 1952.

En dicho plano intercomunal se remarca la continuidad de la masa verde propuesta en el bloque norte, considerando -de poniente a oriente-: el Cementerio General, el cerro-parque Blanco, el parque de 12 hás de Brunner (ahora dividido solo en dos partes por una calle), el cerro-parque San Cristóbal, el "Parque de la Empresa de Agua Potable de Santiago"13 (al oriente del río Mapocho, hoy "Parque del Bicentenario" en Vitacura) y el Club de Golf Los Leones ${ }^{14}$, en el momento en que este último ya tenía plantados 6.872 árboles de distintas especies en $1936^{15}$

\section{Lo realizado del plan Brunner en el polígono de Recoleta e intervenciones posteriores}

Aun cuando el Plan Brunner para la comuna de Santiago estuvo vigente durante 50 años -1939-1989-, el espacio asignado al parque uniendo los cerros sólo vio la prolongación de la avenida Perú (ex "Avenida de Circunvalación") al norte para empalmar con El Salto -realizando el proyecto de Brunner más de 30 años después-, en los momentos en que desaparece el Club Nacional de Tiro para dar paso también al seccional "Tupac Amaru" (CORMU, 1971).

Desarrolló este último una supermanzana -ocupando 6,7 hectáreas de lo que debía ser el parque citado en el proyecto de Brunner- por fusión de cuatro manzanas situadas entre Av.

\footnotetext{
12 Al respecto, puede verse Pavez Reyes, 2012.

13 Fte.: MINVU: "Plano Oficial de Urbanización de Las Condes", 1945, D.G.O.P., Departamento Arquitectura, Sección Urbanismo (Fdo.: L. Muñoz M. Planificación comunal a partir de planificación intercomunal c. 1936, del mismo autor). 14 El $1^{\circ}$ de Agosto de 1934, la Sociedad Anónima de Deportes Club de Golf Santiago, adquirió 71 hectáreas en los faldeos del Cerro San Luis. Rápidamente se dio comienzo a la limpieza, aradura, construcción de desagües y tranques de riego en el terreno. Información en página web del Club de Golf Los Leones: http://www.golflosleones.cl/19101936/ [Consulta 02-10-2013].

${ }_{15}$ Información en página web del Club de Golf Los Leones: http://www.golflosleones.cl/1910-1936/ [Consulta 02-102013].
} 
Perú por el oriente, calle El Salto Chico por el poniente, calle Unión por el norte y calle Schlack por el sur.

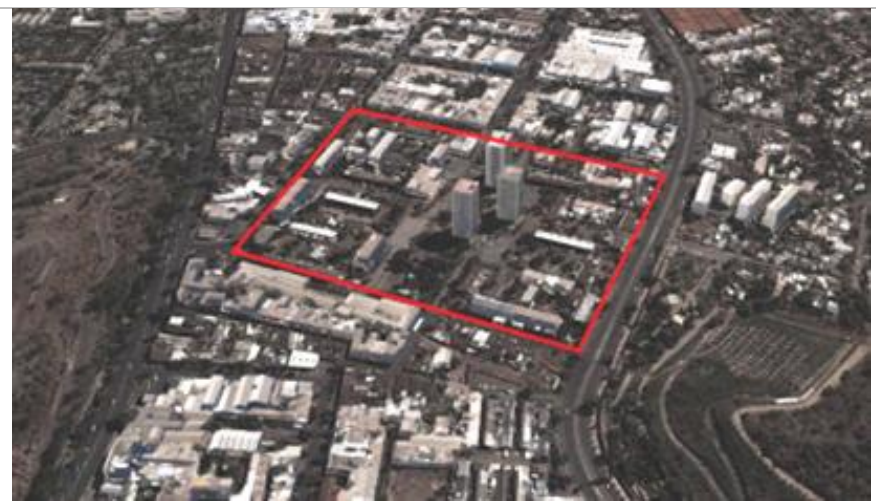

Fig.11.- Remodelación Tupac Amaru, 1971. Vista oblicua: Google Earth, 01-10-2013.

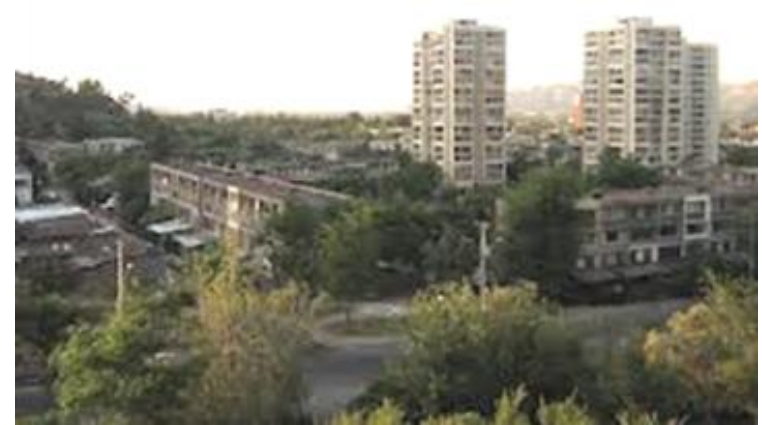

Fig. 12- Villa San Cristóbal.

Fte.: Panoramio Google Eath [01-10-2013].

Del proyecto de Brunner solo se realizaron varios tramos de vías locales, y el tramo que unió, finalmente, las avenidas Perú y El Salto, pero ningún subsistema vial y verde local completo (Fig.14.).

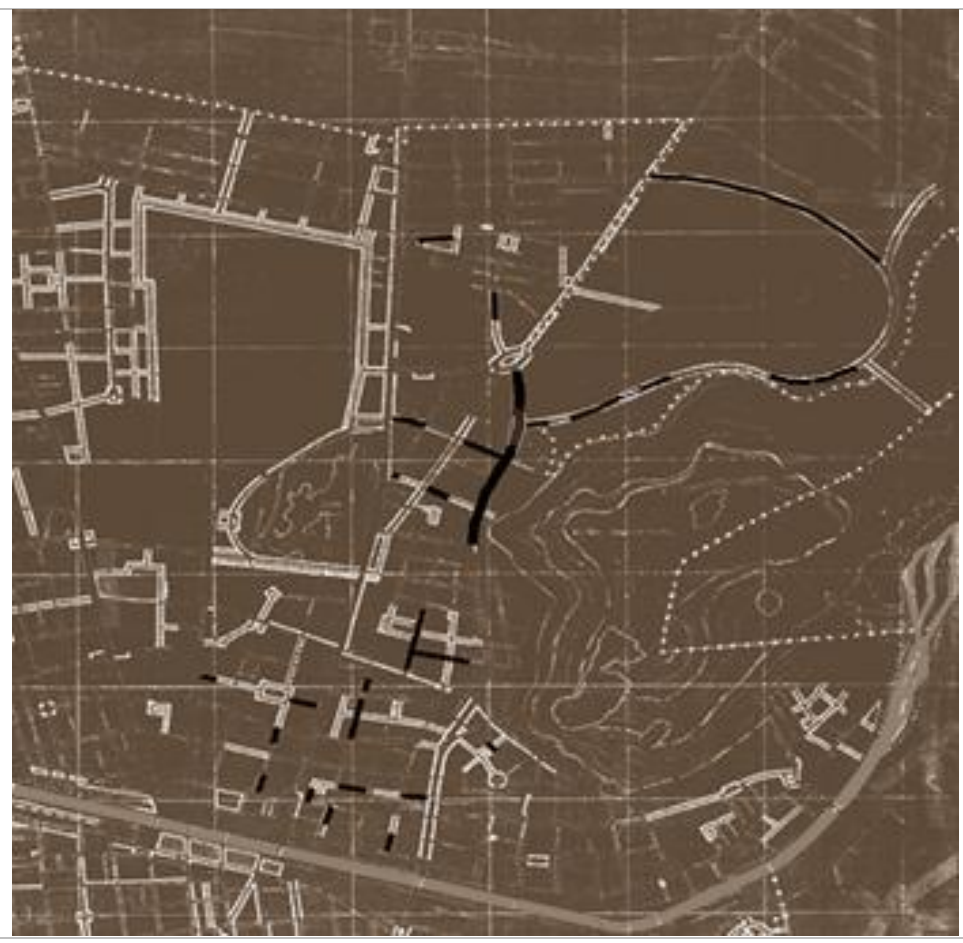

Fig. 13.- Sección del plano P.O.U. Brunner 1934/39 -polígono Recoleta- (color invertido para la presente publicación), con sus proposiciones en blanco remarcado. En negro, los trazados efectivamente realizados. Fte: Elaboración propia a partir de copia matriz del plano P.O.U. 1934/39, en D. Urbanismo. (c)

A diferencia del polígono de Independencia, en Recoleta no se realizaron los parques y plazas de tamaño medio y menor propuestos. 


\section{URBANISMO}

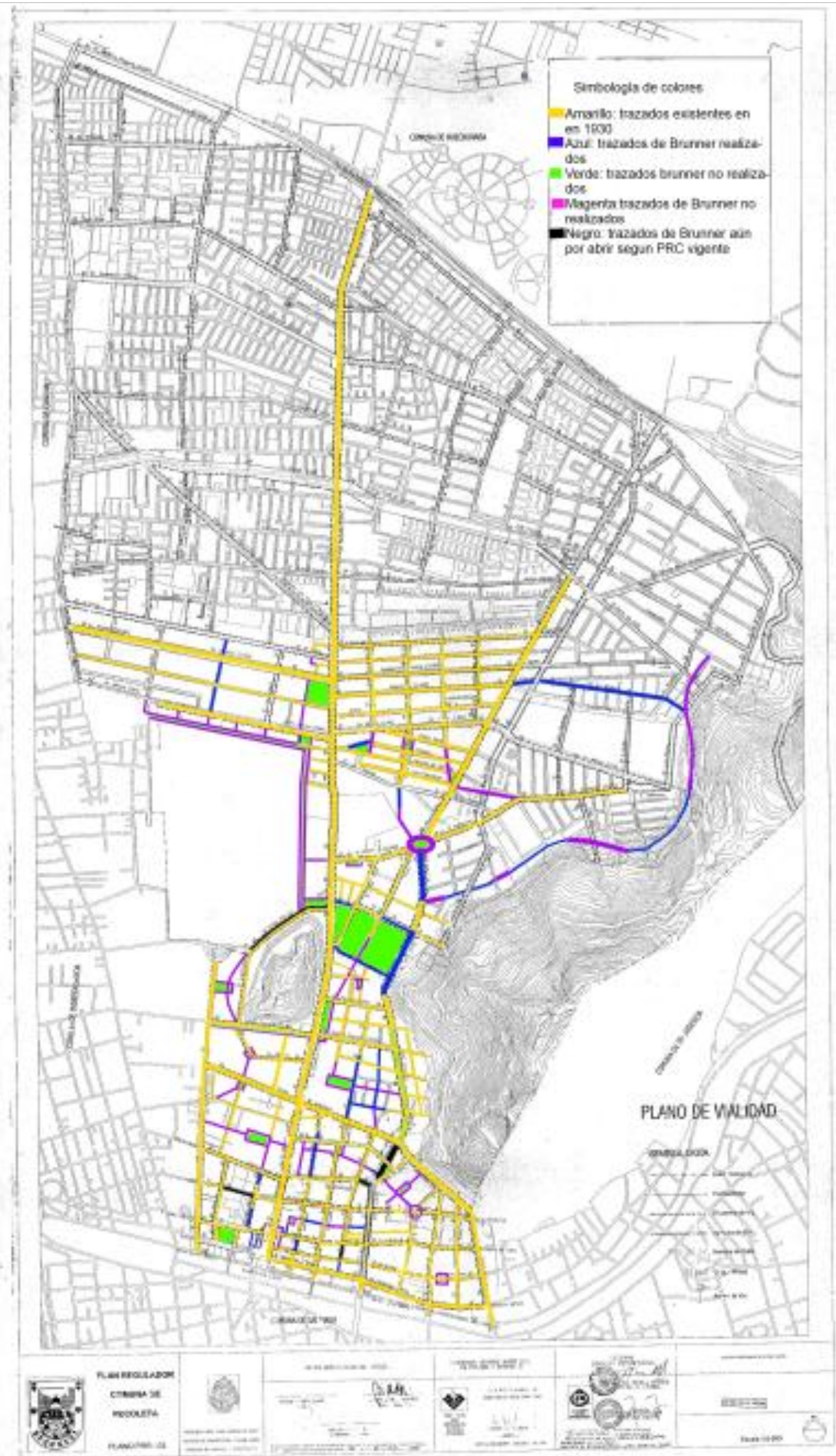

Fig.14.- Trazados de Brunner 1934 (planificación oficial de la Comuna de Santiago), sobre plano de vialidad existente y proyectada vigente de la Comuna de Recoleta (Plano PRR 03. Fte.: I. M. Recoleta, 2013). En color, por elaboración propia. AMARILLO: algunas vías existentes en 1930.

AZUL, trazados de Brunner realizados. VERDE: espacios verdes Brunner, no realizados. MAGENTA: trazados viales no realizados. NEGRO: trazados viales Brunner, que aún figuran para apertura o ensanche en Plan Regulador de Recoleta vigente al 2013. (c) 


\section{Ejercicios académicos y un proyecto profesional en el entorno del cerro Blanco.}

Se asume que la docencia en Urbanismo debe comprender tanto el conocimiento como la praxis. La ciudad es el resultado de un proceso dinámico que se hace día a día a través del tiempo. La historia urbana da cuenta de las capacidades transformadoras del hombre, y en último término, de las específicas relaciones de éste con la naturaleza en su conjunto y a la que pertenece. El fundamento básico de la ciudad puede ser visto como el conjunto de relaciones que se establecen entre el conjunto de predios, de manera que cualquier acción concreta objeto de proyecto -esto es sobre un predio individual-, puede desencadenar un proceso autoorganizativo en el conjunto, de manera que la acción trasciende el interés sobre el propio predio pasando a formar parte de la esfera de "lo público". El conocimiento de la ciudad y de la acción sobre la misma tiene que ver con el conocimiento de esta estructura de tipo relacional ${ }^{16}$.

La inserción del proyecto urbano en el marco de la complejidad pasa por una aproximación responsable a las repercusiones sobre el conjunto de dimensiones del hecho urbano, de la resolución específica de los aspectos morfológicos a través del diseño. Pero, sólo en el uso social de los espacios producidos se puede hablar de espacios urbanos estéticamente validados en su tiempo. Así, el conocimiento meramente formal de espacios aclamados o incuestionables de la experiencia urbana no puede ser extrapolado a un repertorio de soluciones si se ignora su implicación concreta ${ }^{17}$.

La concepción de la ciudad y el territorio como espacios dinámicos supone estados sucesivos de equilibrio y cambio, donde la metodología tradicional de proyecto como definición precisa de un estado final cerrado debe ser cuestionada, y pese a ello o sobre todo a causa de ello, notablemente enriquecida ${ }^{18}$.

\subsection{Los trabajos de los viejos estudiantes en 1930}

Observamos que los arquitectos estudiantes de postítulo en el Seminario de Urbanismo dictado por K. Brunner en 1930, habían explorado en sus ejercicios diversas formas de urbanización en el entorno oriental del cerro Blanco, desde aquellas con viviendas unifamiliares rodeadas de jardín, con baja densidad, hasta viviendas colectivas en altura y densidad medias liberando, de esta forma, espacio intersticial para jardines colectivos al pie de la residencia, (Figs. 15 y 16, respectivamente). En ambos casos, una disposición más o menos homogénea de numerosos espacios verdes - públicos y privados de escala de vivienda y/o vecindad- entre las laderas de los cerros Blanco y San Cristóbal, vendrían a generar una cierta continuidad deseable para incrementar aún más los servicios prestados por la masa verde.

La proposición del arquitecto alumno E. U. Ulriksen, (Fig.15), señalaba además un acceso en zig-zag al cerro Blanco en su eje transversal por la ladera oriente, y otro para empalmar con un camino y mirador - "La Esplanada"- por la ladera poniente. Una vía ajardinada-paseo se planteaba entre ambos cerros, uniendo las avenidas Recoleta y "de Circunvalación". Al sur de S. Dumont, y al oriente de la iglesia Recoleta Dominica, se proponía otra vía-paseo con los mismos fines que la primera, dejando a este edificio principal aislado por todo su entorno.

En el caso del ejercicio realizado por el estudiante S. Perelman, (Fig.16), este se ubicaba al poniente de la "Avda. de Circunvalación", y entre Santos Dumont, Dominica y Tabaré. Los bloques de viviendas colectivas se organizaban en torno a un eje paralelo a Tabaré, -a modo de centralidad verde vecinal-, disponiéndose un edificio en hemiciclo en la zona sur, junto a dos bloques a modo de umbral.

RUIZ S., Javier, 2002, op.cit.

Idem.

18 Idem. 


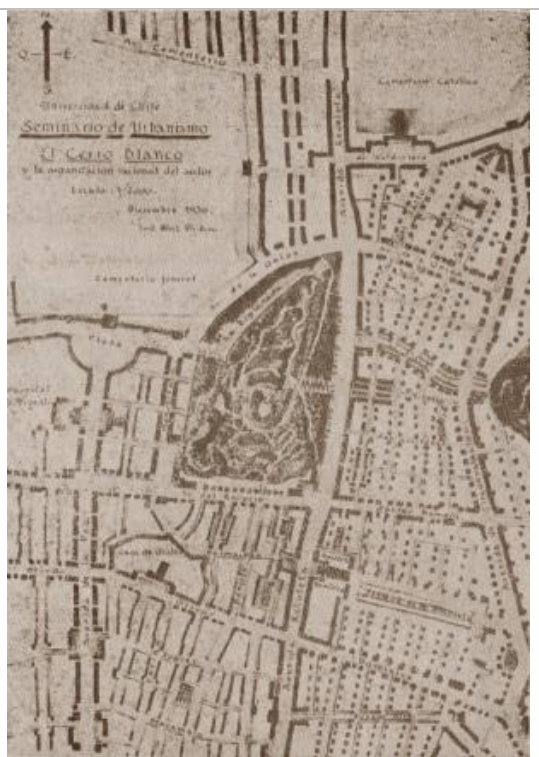

Fig.15.- Proposición del arquitecto alumno E.U. Ulriksen. Seminario de Urbanismo por K. Brunner, 1930.

Fte.: Brunner 1932, p.100.

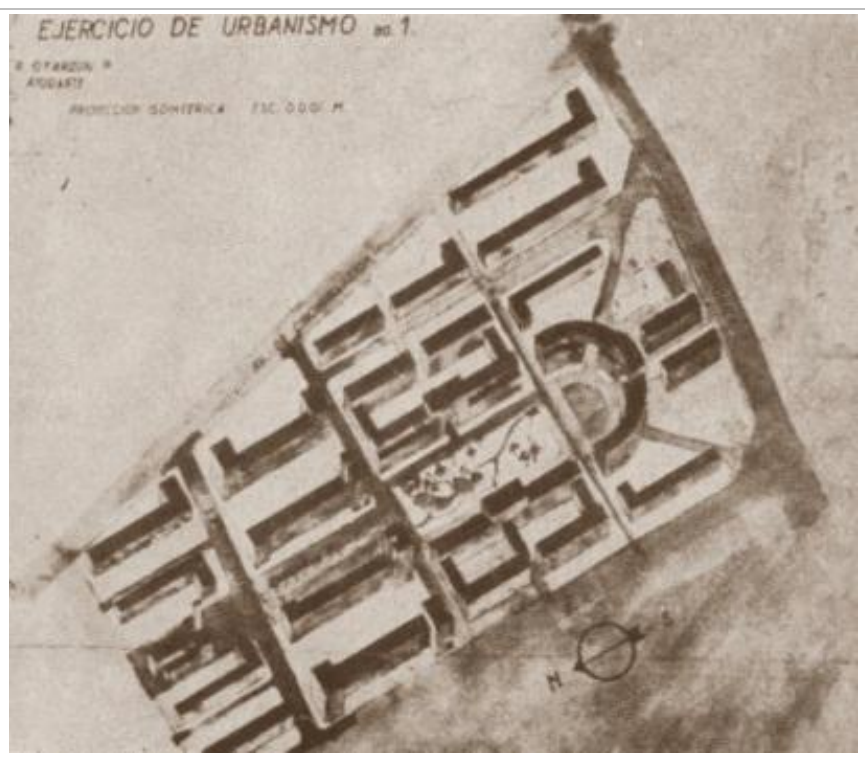

Fig.16.-Proposición del arquitecto alumno S. Perelman, al poniente de la "Avda. de Circunvalación", y entre Santos Dumont y Domínica, (Norte a la iz.). Seminario de Urbanismo por K. Brunner, 1930.

Fte.: Brunner 1932, p.101.

Cabe destacar en este punto que el estudiante Perelman seguía posiblemente a Brunner al elevar densidad de personas y edificación, en el pericentro de Santiago. Había señalado Brunner ${ }^{19}$ :

[...] la valorización de terrenos colindantes al centro comercial [centro principal de la ciudad de Santiago] debido a su escasez y a la esperanza de un futuro aprovechamiento más lucrativo, siempre tiene tendencias a subir, como un fenómeno lógico, que no se puede eliminar; esto constituye un motivo más para escalonar el aprovechamiento admisible desde el centro hacia afuera, estableciendo en estos barrios una edificación más alta y más densa que en las zonas netamente residenciales que siguen más afuera.

\subsection{Anteproyecto de Ciudad Universitaria junto al cerro-parque Blanco para la Universidad de Chile en los 50'.}

Los arquitectos Rodulfo Oyarzún y Elsa Fuentes, propusieron la erradicación de la Vega Central y su reemplazo por una Ciudad Universitaria para la Universidad de Chile, en la cual el cerro Blanco quedaba incorporado a ella. Comprendía grandes conjuntos de viviendas para funcionarios, académicos y estudiantes. Disponía amplias zonas verdes y espacios deportivos y de recreación que rompían la cuadrícula, aunque mantenía, en general, unos trazados ortogonales organizados a partir de una suerte de cardo y decumano, favoreciendo sus calles las vistas al oriente y poniente, y el acceso al cerro Blanco. Este último también esencialmente verde, aunque con algunos edificios. Adicionalmente un diseño lineal se desplegaba al sur del río Mapocho, entre calle Puente y 21 de Mayo, para comunicar finalmente al conjunto universitario con la Plaza de Armas de Santiago ${ }^{20}$.

19 Brunner, 1932, p. 20.

20 PAVEZ R. M. Isabel. "Precursores de la enseñanza del urbanismo en Chile. Período 1928-1953". En: DE ARQUITECTURA N³, F.A.U. de la Universidad de Chile, octubre de 1992, pp.2-11. (Dibujo de E. Lyon, a partir de UNIVERSIDAD DEL BIO BIO, F.A.C. Rodulfo Oyarzún PH. Arquitecto, Concepción, Chile, abril de 1988. 


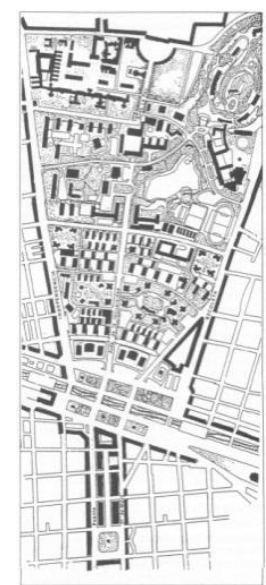

Fig.17.- Anteproyecto de Ciudad Universitaria U. Chile junto al cerro-parque. Arqtos. $R$. Oyarzún y Elsa Fuentes. Fte.:Pavez R., 92, op.cit.

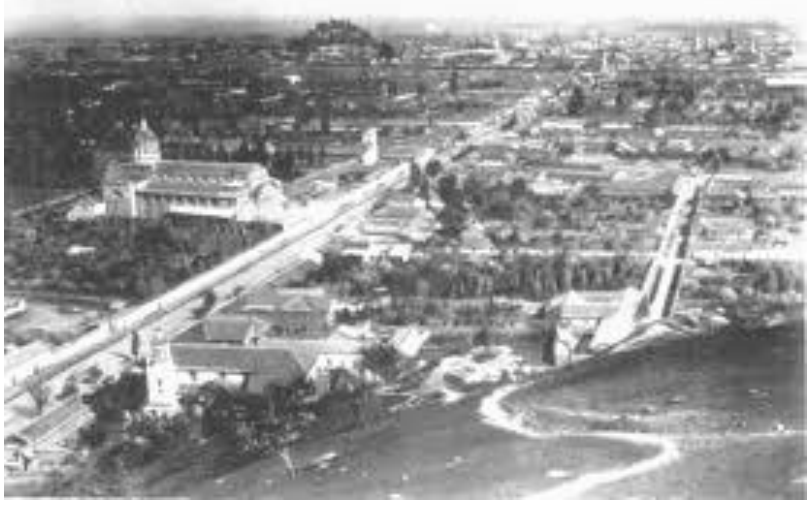

Fig.18.-Vista desde el cerro Blanco sobre parte del polígono abordado por la Ciudad Universitaria en Fig.17, y focalizando el cerro Santa Lucía. Fte.: Archivo Andrés Bello.

\subsection{Exploración de Diseño Urbano entre los cerros-parques San Cristóbal y Blanco en un ejercicio académico del pregrado en 2013}

Como producto derivado de la investigación citada al inicio de este escrito, cuatro equipos de estudiantes del pregrado de la carrera de Arquitectura ${ }^{21}$-de un total de catorce abordando diversos polígonos del bloque metropolitano norte de Santiago, - exploraron las posibilidades del Diseño Urbano en el polígono de Recoleta, entre los cerros Blanco y San Cristóbal, intentando generar de alguna forma, la continuidad verde entre los cerros San Cristóbal y Blanco, a la vez que superar las actuales formas de renovación urbana en esquema de torres de alta densidad puntual.

El trabajo de los estudiantes consideró el planteamiento general del problema, los antecedentes históricos -antes referidos-, un cuerpo de conceptos orientadores, y unos objetivos en los siguientes términos:

En el marco actual de una "planificación estratégica" de las ciudades centradas en una retórica de términos político-económicos (los mercados como fundamento de la urbanización del territorio), la evolución urbana del pericentro de Santiago se está produciendo mediante intervenciones arquitectónicas y urbanas puntuales que elevan considerablemente la altura de la edificación y la densidad de población, sin referencia a un diseño urbano más sustentable.

El proceso de renovación urbana en aceleración es precipitado por la expansión del mercado inmobiliario, la Ley de Renovación Urbana, y la actividad comercial en las comunas del pericentro; se observa, además, el impacto de las Líneas de Metro existentes y en proyecto con consecuencias en un radio de, al menos, $500 \mathrm{~m}-$. No se provee el espacio público y los diversos servicios requeridos por la antigua y nueva población esperada -incluidos los ambientales-, no se preserva las vistas hacia el macro paisaje ni las cualidades de los elementos patrimoniales que determinan la identidad específica del pericentro, no se contempla acciones para evitar el reemplazo social esperable (no necesariamente "gentrificación" en el

21 FAU U. Chile, Pregrado: Urbanismo 2 (Otoño 2013), Prof. M.I. Pavez R. 
pericentro de Santiago de Chile) toda vez que la presencia del Metro eleva los valores del suelo.

Se va perdiendo stock construido y espacio intersticial existente indiscriminadamente, para ser reemplazado por proyectos que no participan de una política de ocupación del suelo donde se establezcan mejores relaciones entre espacio público y privado, entre naturaleza y artificio, entre edificación nueva y edificación patrimonial, entre población nueva y antigua.

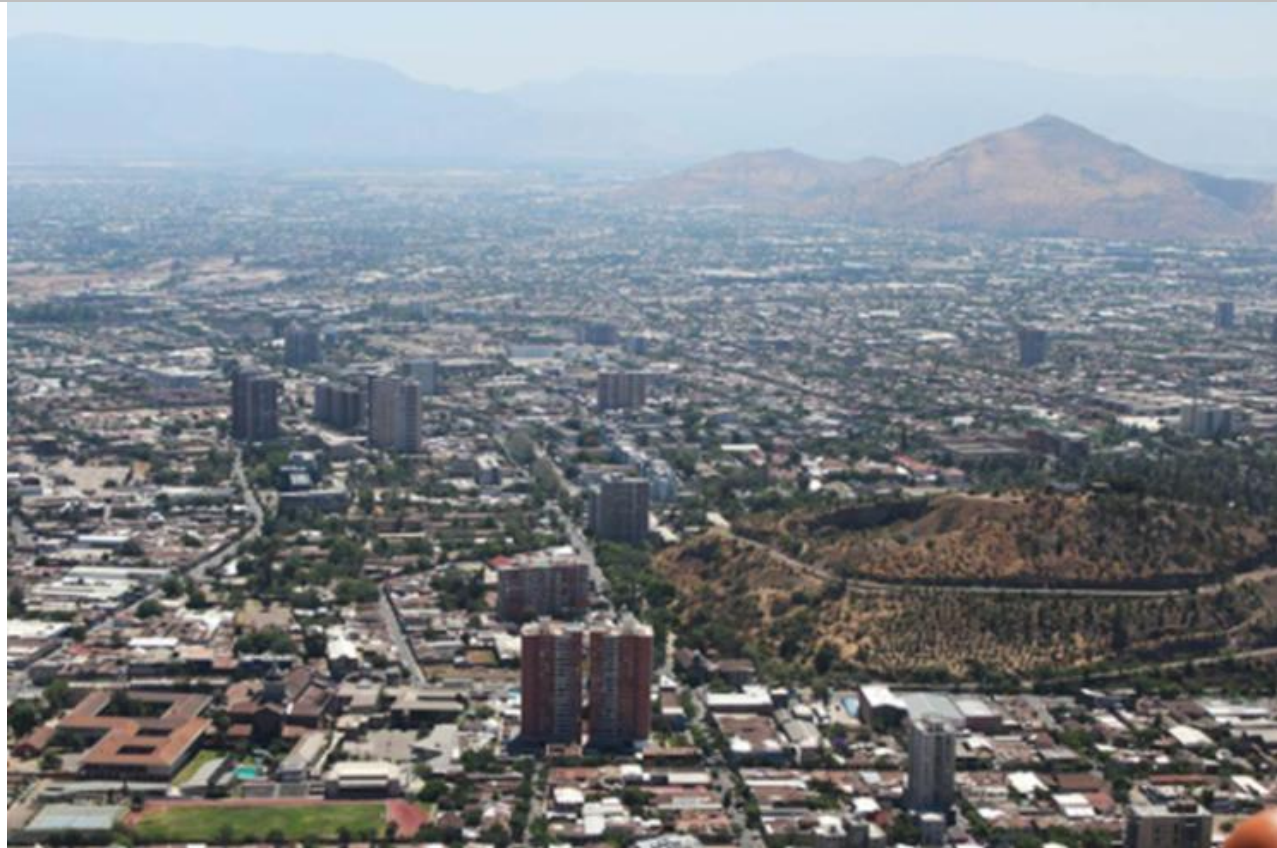

Fig.19.-Vista al poniente desde el cerro San Cristóbal, con el cerro Blanco en primer plano. Foto. C. Quilodrán, 2013.

Para efectos del ejercicio docente, entre los requerimientos para la trasformación y evolución de las áreas urbanas pericentrales se priorizó la necesidad de recualificación de los terrenos eriazos o en obsolescencia; la necesidad de la emergencia de la matriz verde en la ciudad -los intersticios urbanos- (modelo tesela, corredor, matriz ${ }^{22}$ ); el incremento de la diversidad en la ciudad; la recentralización de los equipamientos de acompañamiento ${ }^{23}$ a la vivienda (promoción de la paseabilidad peatonal), la calidad de vida en el espacio público de la ciudad (la ciudad implícita en los edificios, la calidad de la 'paseabilidad' peatonal, e incentivos para la permanencia en el espacio público ${ }^{24}$.

Dado que en la ciudad latinoamericana la presencia de lo natural es un rasgo significativo que interactúa con un tipo específico de trazado urbano, el trazado ortogonal, se estima necesario profundizar en las pautas proyectuales posibles a partir de dicho tejido, fuertemente estructurante, y con un gran valor de identidad ${ }^{25}$.

El polígono de estudio en Recoleta, recorta su silueta contra un fondo escénico natural notable especialmente al oriente y poniente, en escala de macro paisaje no transformado. El trazado ortogonal permite una visibilidad particular al marcar las visuales y genera perspectivas focales caracterizadas por la existencia de líneas paralelas u objetos alineados que convergen hacia

\footnotetext{
FORMAN y GODERON, 1986.

AUGÉ, VIRILIO, ASCHER, citados por NASELLI, 2006, p.9.

POZUETA et al. 2009 op cit.

NASELLI, César, "La vigencia de la cuadrícula", en NASELLI et al, 2006, pp.6-19.
} 
elementos naturales. La percepción de la naturaleza como fondo escénico potencia la calidad ambiental y enriquece las imágenes y paisaje del polígono de Recoleta.

La armónica integración entre el subsistema natural y el artificial contribuirá a recualificar el polígono de estudio en términos morfológicos.

\subsubsection{Proposición básica de conjunto}

Para su proposición final el equipo de estudiantes seleccionado para efectos de este escrito, María Ignacia Fernández Barrientos, Leonardo Gaete Valdés, Patricia Grandy Tudela y Carolina Trincado Ruiz, consideraron el polígono ubicado entre Recoleta, Arzobispo Valdivieso, Avda. Perú y Santos Dumont.

Cabe destacar que en la realidad actual, frente a lo que debía ser el parque del Plan Brunner, está habilitado el borde del Parque Metropolitano del San Cristóbal entre las calles Delfina León y San Cristóbal. Se trata del "Parque Bicentenario de la Infancia"26, desde 2012 (Avda. Perú 1001), con una superficie de 4 hás.

Los estudiantes definieron, en primer lugar, una vía cardo (eje Puma - Díaz Ramos) uniendo A. Valdivieso con S. Dumont, y un sistema decumano (par Schlack - Vera). Este último contempla un espacio verde central con una línea de agua en toda su longitud, señalando el paso del canal La Pólvora (Figs.20 y 21), el cual vemos en un plano de principios del siglo XX corriendo paralelo al canal El Carmen para descender luego hacia el plano y, al llegar al cerro Blanco, doblar al norte en un trazado al poniente de calle Recoleta ${ }^{27}$.

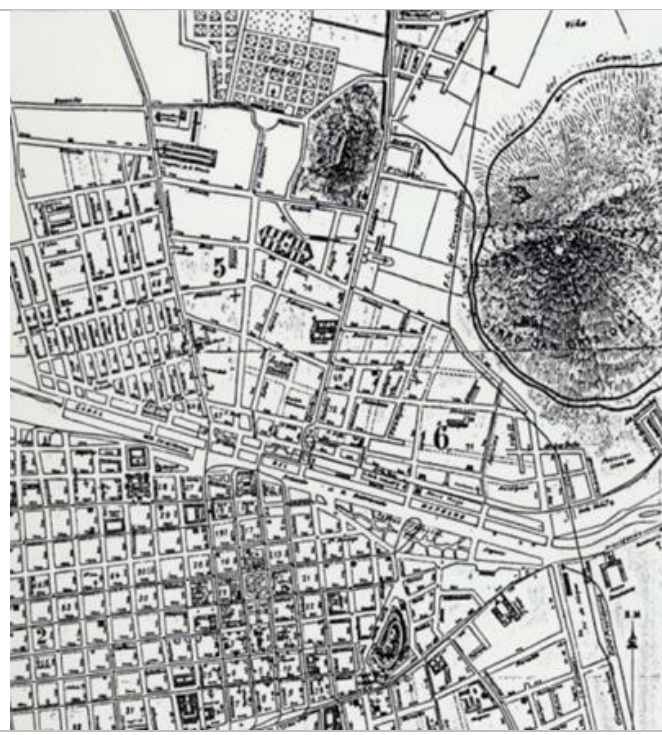

Fig.20.- Sección de "Plano de Santiago 1905", donde se observa el antiguo canal La Pólvora atravesando el polígono entre cerros.

Aquilino García, dibujante, en: Martínez, R., 2007, op.cit., p. 89 (original 53 × 69, plano completo b/n).

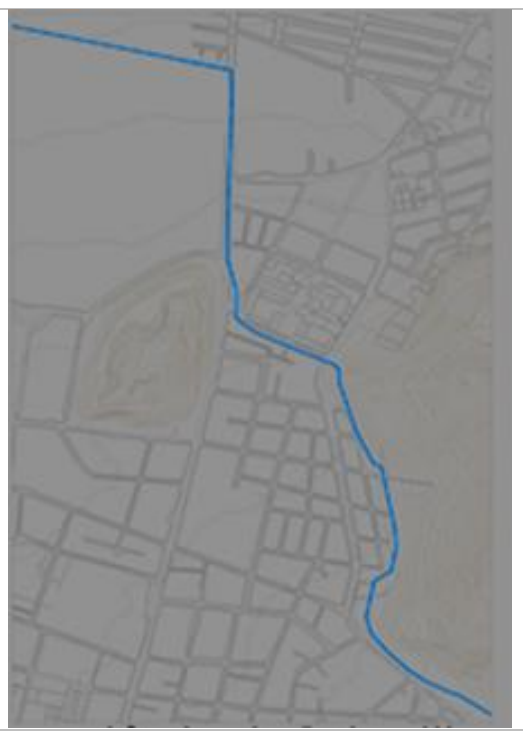

Fig.21.- Recorrido actual del canal La Pólvora, vigente, el cual posee más influencia en el medio urbano que el canal EI Carmen, si bien cruza en varias partes de la comuna abovedado bordeando el Cerro San Cristóbal. Tiene un total de $\mathbf{3 . 5 0 0} \mathbf{m}$ de largo dentro de la comuna de Recoleta.

26 Arqtos. A. ARAVENA, V. OdDó, J. CERDA, F. GARCÍA-HUIDOBRO, D. TORRES, G. ARTEAGA, R. TORREJÓN, y colaboradores G. LARRAIN y R. EMMONS.

27 Cabe destacar que se recomienda normar en el plan las zonas de restricción de canales, posibilitando el despeje de construcciones que se localicen dentro de éstas, fundamentalmente en las zonas donde el canal transita a rajo abierto. En cuanto a los trayectos entubados de los canales, es necesario normalizar las construcciones que se encuentren sobre éstos, sobre todo si el canal pasa por predios privados. 
Este sistema, uniendo los cerros, se dispuso con un perfil aproximado de $70 \mathrm{~m}$ entre líneas oficiales y un largo de $330 \mathrm{~m}$ aprox. (1,5 hás), uniendo Recoleta y Avda. Perú. Se intenta complementar esta superficie verde, como se verá más adelante, mediante parches verdes vecinales en el centro de las manzanas y en parte de los 4 sub-polígonos determinados, asociados a diversos modelos de ocupación de las manzanas explorados.

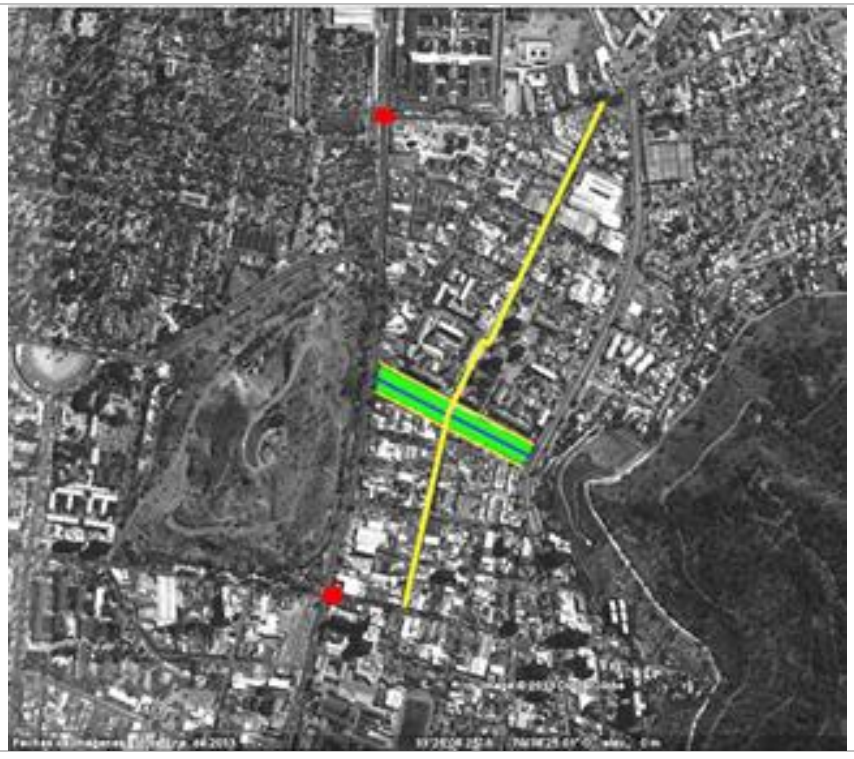

Fig.22.- Proposición de los estudiantes 2013. Ejes interiores relevantes. Estaciones de Metro Cerro Blanco y Cementerios.

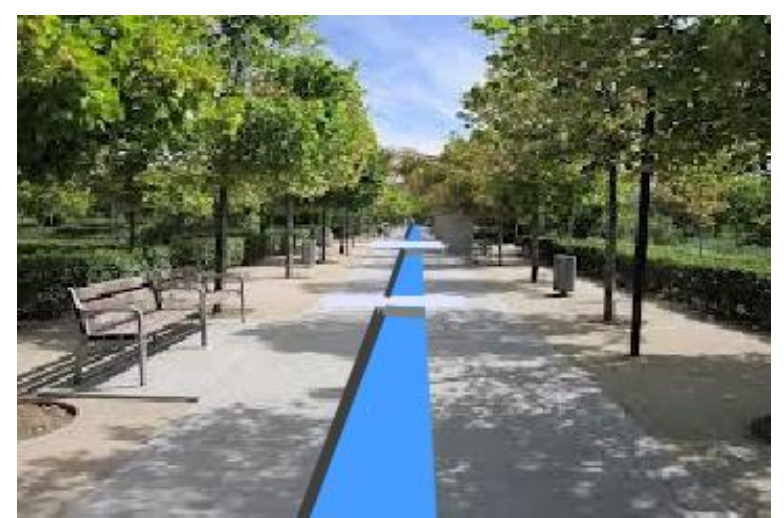

Fig.23.- Paseo entre cerros. Montaje a partir de Google Imágenes.

Dibujo Sobre foto vertical Google Earth 2013.

El paseo verde (Figs. 22 y 23), propuesto junto al borde sur de la remodelación Tupac Amaru (hoy Villa San Cristóbal) logra una superficie de 1,5 hás (300 m x 50 m).

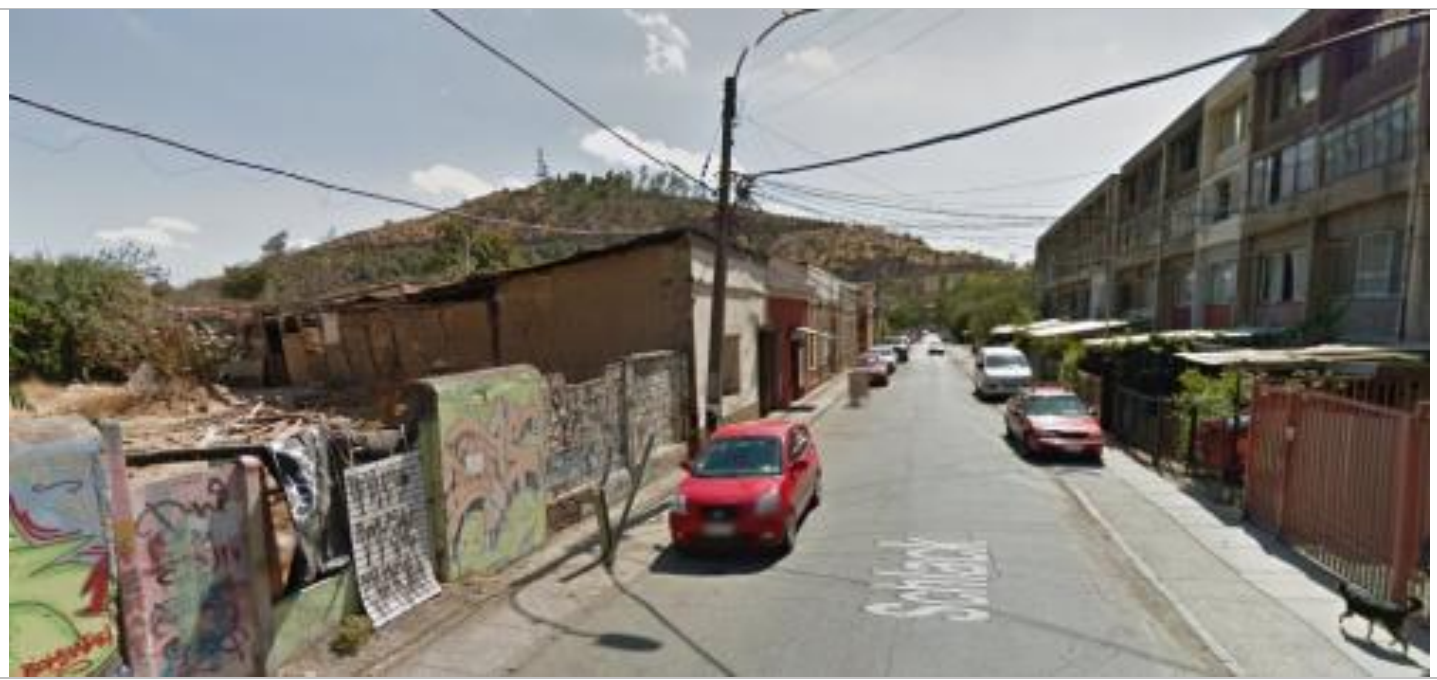

Fig. 24.- Vista hacia el cerro Blanco, donde se observa el grado de obsolescencia del polígono que ocuparía el paseo verde propuesto para unir los cerros Blanco y San Cristóbal. A la derecha el límite sur de la remodelación Tupac Amaru.

Fte.: Panoramio, (21-10-2013). 
De alguna forma, aunque con mayor superficie y alcance, se re-produce el esquema de la llamada "Plaza Central" que Brunner dispuso, también en sentido oriente-poniente en el polígono de Independencia, y que existe hasta hoy bien conservada (280 m x 40 m, y 1,12 hás), Fig. 25.

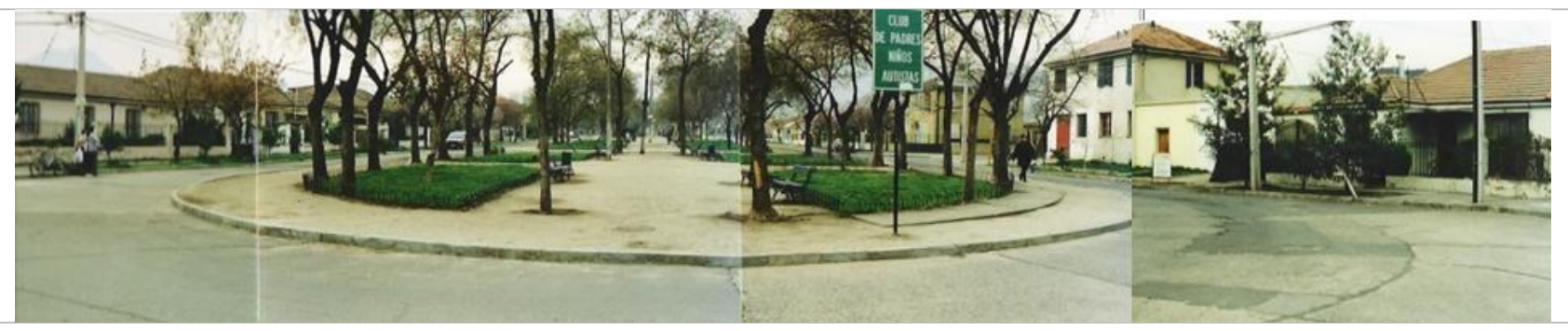

Fig.25.- Plaza Central, K. Brunner, 1934. Polígono Independencia. ( $280 \mathrm{~m}$ de largo por 40 de ancho, con 1,12 hás).

Foto. M.I.P. 2000. (c)

\subsubsection{Algunas formas posibles de organización de las manzanas en los cuadrantes, y sus parches verdes.}

En segundo lugar, y a partir de la opción de una suerte de escalonamiento del aprovechamiento admisible desde el centro de Santiago hacia afuera, se propone en el polígono estudiado una edificación de altura y densidad media, organizando manzanas completas, considerando una mixtura de usos compatibles con la residencia, y espacios verdes de vecindad. Ella podría producirse de varias formas:

MODELO A, el que articula edificación en bloques y torres residenciales, liberando espacio verde intersticial en modalidad abierta. Ordena los espacios abiertos y de circulación de acuerdo a una transición desde lo urbano público (vías y otros), pasando por lo urbano semi-público (equipamientos y comercios vecinales), y grupal público (espacios verdes públicos de vecindad).

Este esquema existe actualmente en el polígono, aunque con limitaciones, y está representado por la remodelación Tupac Amaru (Villa San Cristóbal) ${ }^{28}$. Proyectada en el marco de "la ciudad de la transición al socialismo" (Gobierno de S. Allende), no se hizo "tábula rasa" - al modo de la remodelación San Borja ("la ciudad de la revolución en libertad", Gobierno de Frei Montalva)-, sino que se intentó dialogar con la memoria colectiva; propuso la re-radicación en el mismo lugar de los habitantes encontrados en el lugar; asumió el trazado urbano encontrado, reconociéndolo y adaptándose a él (fusión de 4 manzanas); definió las diversas jerarquías del espacio de interacción proveyendo diversas escalas de integración ${ }^{29}$.

28 RAPOSO y VALENCIA, 2004, (b), cit.

29 Se proyectó para 3.580 residentes en 716 viviendas en bloques de 2 pisos de vivienda continua, bloques de 4 pisos con departamentos en dúplex, y en 2 torres de 17 pisos (534 habitantes por hectárea neta predial). 


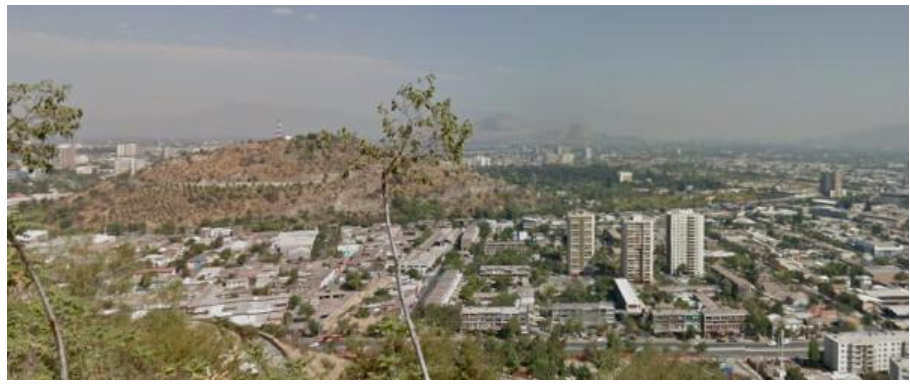

Fig.26.- La remodelación Tupac Amaru (Villa San Cristóbal, a la der.) con el cerro Blanco y el Cementerio General al fondo.

Fte.: Panoramio Google Earth [8-10-2013].

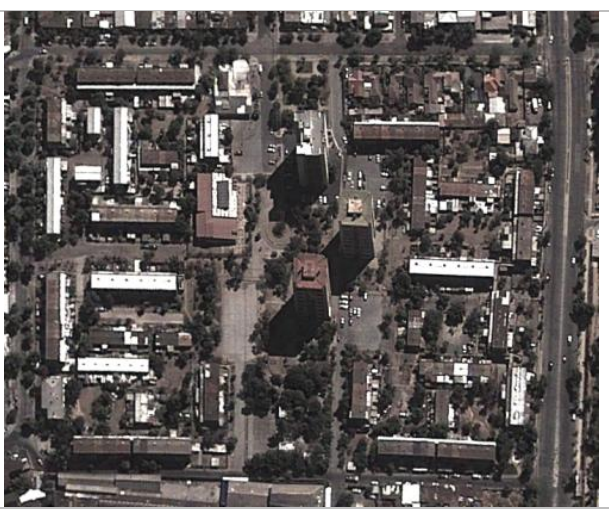

Fig.27.- Vista Vertical remodelación Tupac Amaru (Villa San Cristóbal). Fte.: Google Earth [8-10-2013].

MODELO B, de edificación en altura y densidad media baja a media alta, en manzana cerrada moderna de promoción unitaria, con servicios y comercio de acompañamiento a la residencia en primer piso exterior e interior ${ }^{30}$, aportando también con ello animación y promoción de la paseabilidad peatonal. Para este mismo objetivo, las manzanas consideran pasajes peatonales y, en su centro, los espacios verdes de escala vecinal (grupal semi público). En este esquema la vegetación queda más protegida, el juego de los infantes está mejor vigilado, el comercio en primer piso en frentes exteriores, e interiores, contribuyen a un uso de la ciudad en un arco temporal cotidiano más extendido. Este modelo parece indicado especialmente en las manzanas al poniente de la centralidad norte-sur propuesta, las que están en el área de impacto directo de la Línea de Metro por Recoleta (Estaciones Cerro Blanco y Cementerios).

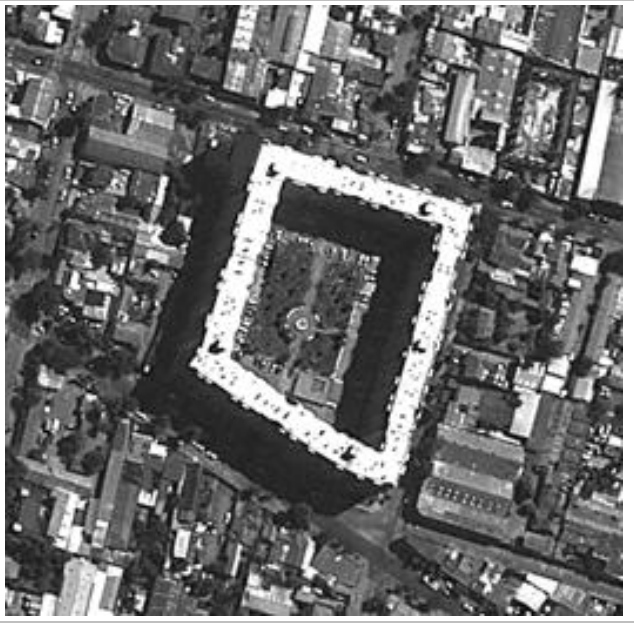

Fig.28.-Manzana cerrada moderna de promoción unitaria.

Fte.: Fotografía vertical Google Earth [8-10-2013].

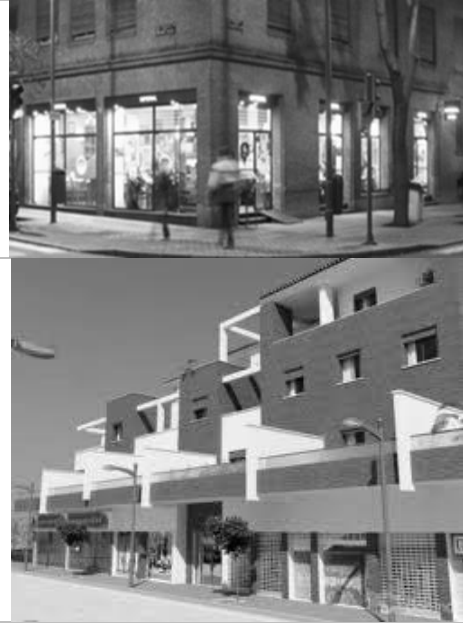

Fig.29.- y 30.- Primer piso, con usos compatibles con la residencia, aportando comercio, animación y mayor seguridad urbana al peatón.

Fte.: Google Imágenes [8-10-2013].

30 El primer piso corresponde a la "planta baja" en Chile. 
Variante del anterior, es un modelo de edificación en altura media baja a media alta en manzana cerrada de promoción unitaria, permitiendo mixtura de usos compatibles con la residencia en primer piso, sólo en el exterior, para aproximar ciertos servicios y comercio a los residentes, y con ello promover la paseabilidad peatonal. Los espacios verdes al centro de la manzana, de escala vecinal, ahora corresponden a un espacio grupal privado. Esta variante podría desplegarse al oriente de la centralidad local norte-sur propuesta.

MODELO C, de edificación en altura y densidad media a media alta, en manzana cerrada moderna de promoción unitaria con espacios intersticiales interiores privados. Comprende un espacio central grupal privado, y patios privados en su entorno asociados a los departamentos del primer piso (planta baja) del conjunto, desde los cuales se puede acceder al jardín colectivo privado.

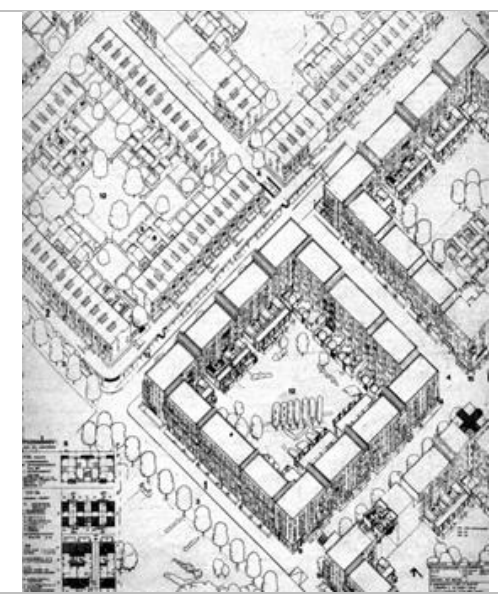

Fig.31.- Organización del conjunto.

Fte.: Finke, et al, 1978, op.cit.

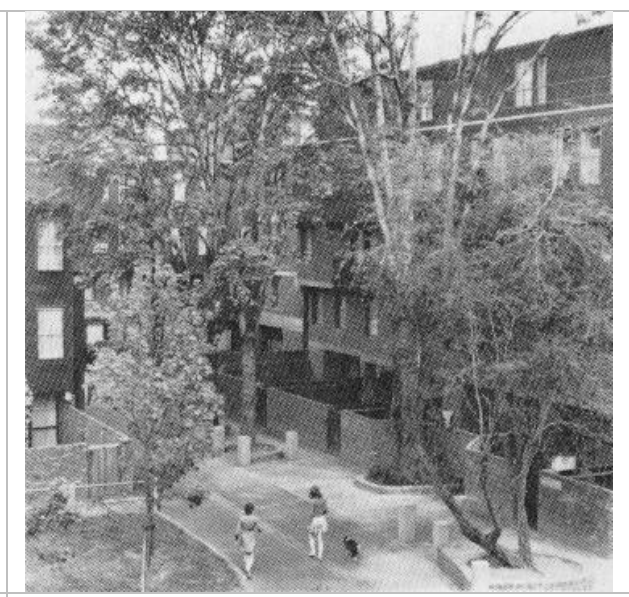

Fig. 32.-Configuración interior privada de la manzana, con patios unifamiliares privados con acceso al espacio grupal privado.

Fte.: Kirschenmann, et al, 1980, op. cit.

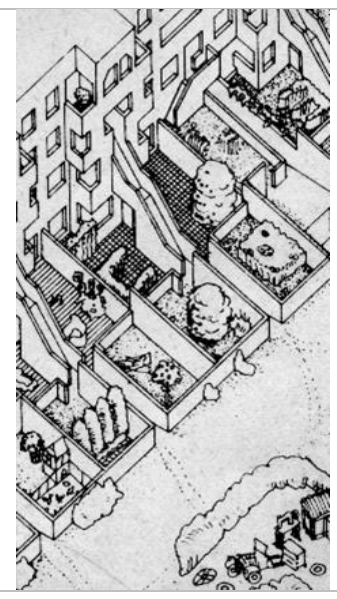

Fig.33.-Configuración interior privada de la manzana, con terrazas y patios unifamiliares privados con acceso al espacio grupal privado.

Fte.: Finke, et al, 1978.

Los modelos seleccionados en esta aproximación pueden dar lugar a ajustes para adaptarse a la existencia de algún edificio de interés patrimonial, a torres de departamentos de promoción individual, con alta densidad, ya existentes, y a otras situaciones especiales. 


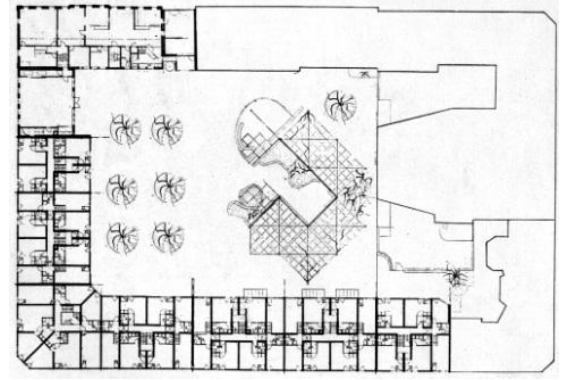

Fig.34.- Manzana con espacio verde privado, coordinando lo existente con lo nuevo.

Fte.: Kirschenmann, et al, 1980, op. cit.

\section{Palabras finales}

Al concluir el curso y su ejercicio -cuando la ciudad actual está viendo deteriorarse gravemente los perfiles de su entorno físico por falta de principios rectores- los estudiantes han llegado a comprender que la ciudad es una obra colectiva que va superponiendo proyectos cuya construcción suele ser, en nuestra realidad, objeto de detenciones, discontinuidades, mutilaciones, desvirtuaciones y rupturas. No obstante, las partes encontradas al momento de nuevas intervenciones, podrían aportar luces para desarrollar proyectos de futuro toda vez que sean apreciadas en su rol en el proyecto original cuya totalidad no pudo ser. Así, el estudio de los planes y proyectos habidos es válido no solo para fines culturales, sino que tiene además una utilidad práctica.

También los estudiantes han profundizado en la naturaleza de la urbanización en un pericentro, y en algunas formas alternativas posibles, comprendiendo la necesidad actual de un mejor diseño urbano para una ciudad más animada, mejor utilizada, más paseable peatonalmente, donde la generación de corredores y parches verdes en diversas escalas, contribuirá a mejorar la calidad de vida de la ciudad metrópoli.

Por último, los estudiantes están conscientes de que un proceso de renovación urbana, suele acarrear la expulsión de la población original en el polígono de intervención. Sin embargo, las experiencias de remodelación comprendiendo a la población original han existido y se siguen realizando en diversas partes del mundo. Explorando en la internet, los términos: "compensación", "cooperación", "derecho preferente de compra por el Estado", "derecho a realojo", "desalojos forzosos en zonas urbanas y derechos humanos", "expropiación", "políticas inclusivas", y "'gentrificación' controlada", son algunos de los términos que se asocian - positiva o negativamente, o con efecto moderador- al tema de la renovación o revitalización de barrios residenciales.

Siendo deseable el realojamiento de los propietarios en el espacio de la misma operación urbanística, por oposición al reemplazo social o, en muchos casos, al aburguesamiento ('gentrificación') de los polígonos urbanos, parece necesario profundizar en la idea del "derecho a permanecer". 


\section{Bibliografía}

BRUNNER von L., Karl. Santiago de Chile, su estado actual y futura formación. Santiago, Ed. K. H. Brunner, 1932. $145 \mathrm{p}$.

BRUNNER, Karl. "Problemas actuales de urbanización", ANALES DE LA UNIVERSIDAD DE CHILE, Año VIII, Número 1, 1930, pp. 12-40.

CORTÉS L., Fernando. "La construcción de la ciudad como espacio público". DE ARQUITECTURA, (8): 14-19, Santiago, F.A.U., U. Chile, 1996.

ESTEBAN NOGUERA, Juli. Elementos de Ordenación Urbana, U. Politécnica Cataluña, 1998, 213 págs.

FINKE, Werner; POPP, Frank; SCHALHORN, Konrad y Hans SCHMALSCHEIDT. Bloques cerrados de viviendas. Edificación en manzanas. Ed. Gustavo Gili, S.A. Barcelona, 1978, 131 págs.

KIRSCHENMANN, Jörg C.; MUSCHALEK, Christian. Diseño de barrios residenciales. Remodelación y crecimiento de la ciudad. Ed. Gustavo Gili, S.A., Barcelona, 1980, 199 págs.

MARTINEZ LEMOINE, René, 2007. Santiago de Chile. Los planos de su Historia. Siglos XVI a XX De aldea a metrópolis. Santiago de Chile, I. Municipalidad de Santiago - DIBAM, 130 págs.

NASELLI, César, Inés MOISSET, Viviana COLAUTTI, Omar PAARIS, y Casio STEVENAZZI. Forma Urbana. Lectura y acciones en la ciudad, I+P Editorial, Córdoba, Argentina, 2006, 103 páginas.

NASELLI, César, "Arquitectura, ciudad, cultura y Sociedad", en Revista Notas del SurArquitectura, Ciudad, Cultura, Sociedad, N03, Córdoba, Argentina, Ed. Facultad de Arquitectura y Urbanismo de la U. Nacional de Córdoba, Abril de 1994, p.p. 30-34.

2007. LIZANA VERGARA, Alejandro. Arquitectura urbana residencial en pericentros metropolitanos. Seminario de Investigación tutelada, $\mathrm{V}$ año carrera de Arquitectura, FAU - Universidad de Chile. Prof. Guía M.I. Pávez, 2007.

PAVEZ R., M. Isabel. Arquitecto Luis Muñoz Maluschka. Planificador Territorial en Chile. Santiago, D. Urbanismo F.A.U. U. Chile, 2012, 129 p.

POZUETA, Julio; Francisco LAMÍQUIZ, y Mateus PORTO, 2009, La ciudad paseable, CEDEX, Madrid, España, 430 págs.

PRINZ, Dieter, Planificación y configuración urbana. Ed. Gustavo Gili, 1983, 335 págs. ilistr.

RAPOSO, Alfonso. "Sobre políticas de vivienda. Fragmentos mnémicos". A R T E O F I C I O N04 / CUADERNOS USACH, [consulta en Internet 01-10-2013].

RAPOSO, Alfonso; VALENCIA, Marco (a). "Modernidad, Diseño Urbano y Utopía: Notas sobre el fundamento político de las acciones de Remodelación Urbana en Santiago. El caso de la CORMU 1966-1973. (Primera parte)". En: REVISTA DE URBANISMO N9, Santiago de Chile, Ed. Departamento de Urbanismo, FAU, U. Chile, marzo de 2004.

RAPOSO, Alfonso; VALENCIA, Marco (b). "Modernidad, Diseño Urbano y Utopía: Notas sobre el fundamento político de las acciones de Remodelación Urbana en Santiago. El caso de la CORMU 1966- 1973. (Segunda parte)". En: REVISTA DE URBANISMO N¹0, Santiago de Chile, Ed. Departamento de Urbanismo, FAU, U. Chile, junio de 2004.

RODÀ, Ferrán. 2003. "La matriz del paisaje. Funciones ecológicas y territoriales", en FOLCH, Ramón (coordinador) El territorio como sistema. Conceptos y herramientas de ordenación. Ed. Diputación de Barcelona, noviembre de 2003, 291 págs. ilustradas; pp.43-55. 
Derivada de RODÀ, Ferrán: FORMAN, Richard TT.; GODERON, Michael. 1986. Landscape Ecology, Nueva York, John Wiley\& Sons, 1986.

RUIZ SÁNCHEZ, Javier. "La enseñanza del urbanismo y la enseñanza de la práctica del urbanismo. Un proyecto docente en el marco de la realidad urbana compleja". En: Cuadernos de Investigación Urbanística $\mathrm{Ci}[\mathrm{ur}] \mathrm{N}^{\circ} 35$, Departamento de Urbanística y Ordenación del Territorio, E.T.S.A. - U. Politécnica de Madrid, julio de 2002: http://www2.aq.upm.es/Departamentos/Urbanismo/institucional/numeros-ciur/ciur-35/

VIOLICH, Francis. Cities of Latin America. Housing and planning to the south. N. York, U.S.A., Reinhold Publishing Corporation, 1944, 241 p. 